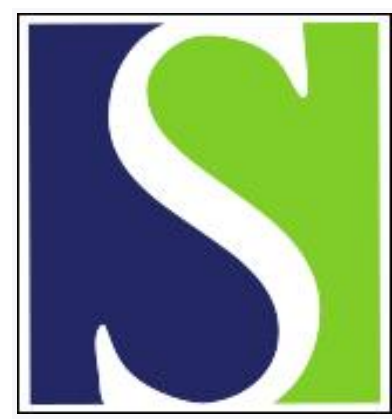

Scand J Work Environ Health 2012;38(6):582-589

https://doi.org/10.5271/sjweh.3310

Published online: 19 Jun 2012, Issue date: 01 Nov 2012

Dose-response relation between perceived physical exertion during healthcare work and risk of long-term sickness absence

by Andersen LL, Clausen T, Persson R, Holtermann A

Affiliation: National Research Centre for the Working Environment,

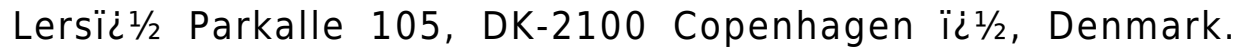
lla@nrcwe.dk

Refers to the following texts of the Journal: $2003 ; 29(6): 431-440$ 2005;31(6):409-437 1999;25(5):387-403 1999;25(2):105-114 2011;37(1):6-29

The following articles refer to this text: 2014;40(4):361-369; 2017;43(1):68-74; 2016;42(6):481-489; 2018;44(2):192-201; 2020;46(4):429-436; 2021;47(8):609-618

Key terms: absenteeism; Dose-response relation; healthcare work; long-term sickness absence; nursing; perceived exertion; physical activity; physical exertion; sickness absence; sickness absence

This article in PubMed: www.ncbi.nlm.nih.gov/pubmed/22714069

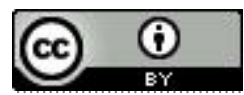




\title{
Dose-response relation between perceived physical exertion during healthcare work and risk of long-term sickness absence
}

\author{
by Lars L Andersen, PhD, ${ }^{1}$ Thomas Clausen, PhD, ${ }^{1}$ Roger Persson, PhD, ${ }^{1}$ Andreas Holtermann, PhD ${ }^{1}$
}

\begin{abstract}
Andersen LL, Clausen T, Persson R, Holtermann A. Dose-response relation between perceived physical exertion during healthcare work and risk of long-term sickness absence. Scand J Work Environ Health. 2012;38(6):582589. doi:10.5271/sjweh.3310
\end{abstract}

\begin{abstract}
Objective An imbalance between physical work demands and physical capacity of the worker may be a risk factor for poor health. Perceived physical exertion provides information about the individual perception of the work demands relative to the capacity to perform the work. This study estimates the risk for long-term sickness absence (LTSA) from perceived physical exertion among healthcare workers.
\end{abstract}

Methods This prospective cohort study comprises 8592 Danish healthcare workers who responded to a baseline questionnaire in 2004-2005 and subsequently were followed for one year in the Danish Register for Evaluation of Marginalization (DREAM), a national register of social transfer payments. Using Cox regression hazard ratio (HR) analysis, controlled for age, gender, body mass index (BMI), smoking, tenure, leisure-time physical activity, psychosocial working conditions, and LTSA during one year prior to baseline, we modeled risk estimates of moderate and strenuous (reference: light) perceived physical exertion during healthcare work for onset of LTSA (receiving sickness absence compensation for $\geq 8$ consecutive weeks) during 1-year follow-up.

Results At baseline, 35.1\%, 39.4\%, and 25.5\% of the healthcare workers experienced, respectively, light, moderate, and strenuous physical exertion during healthcare work. During follow-up, the 12-month prevalence of LTSA was $4.6 \%, 6.4 \%$, and $8.9 \%$, respectively, in these three exertion groups. A dose-response pattern between physical exertion and the risk for LTSA was found (trend test $\mathrm{P}<0.0001$ ). In the multi-adjusted model, the risk for LTSA was 1.31 [95\% confidence interval (95\% CI) 1.04-1.64] for healthcare workers reporting moderate physical exertion and 1.57 (95\% CI 1.23-2.01) for those reporting strenuous physical exertion, referencing those reporting light physical exertion during healthcare work.

Conclusion Moderate and strenuous perceived physical exertion during healthcare work increases - in a doseresponse manner - the risk for LTSA. The possible preventive effect of balancing work demands with the capacity of the worker, to thereby avoid excessive physical exertion, should be tested in randomized controlled trials.

Key terms absenteeism; nursing; perceived exertion; physical activity.

Most European countries have a shortage of healthcare workers (1). A high level of long-term sickness absence (LTSA) among healthcare workers exacerbates this situation (2). Sickness absence for $\geq 8$ weeks is of particular interest because empirical evidence suggests that employees who are absent for such a prolonged period have a substantially increased risk of not returning to work (3). A Danish study found an annual prevalence of LTSA ( $>8$ weeks) of $6 \%$ among healthcare workers (4). To improve health and well-being among healthcare workers as well as to reduce societal costs, knowledge of risk factors for LTSA would help the development of preventive strategies $(5,6)$.
Workers with high physical demands are at increased risk for impaired work ability (7) and LTSA (8). Healthcare work is a high-risk occupation with high physical work demands often performed by women with low physical capacity (9). An imbalance between physical demands of the work and physical capacity of the worker has been suggested as a cause of poor health (10). Due to individual variations in physical capacity (11), similar physical demands of work may be perceived and experienced differently.

In laboratory settings, perceived physical exertion relates closely to work demands expressed as a percentage of the individual physical capacity - both in terms

1 National Research Centre for the Working Environment, Copenhagen Ø, Denmark.

Correspondence to: Lars L Andersen, National Research Centre for the Working Environment, Lersø Parkalle 105, DK-2100 Copenhagen Ø, Denmark. [E-mail: 1la74@outlook.com] 
of cardiovascular (12) and muscular work loadings (13). Thus, to some extent, perceived physical exertion reflects the balance between physical work demands and physical capacity of the individual. Cross-sectional studies have reported positive correlations between perceived physical exertion and sick leave among healthcare workers (14, 15). Perceived physical exertion during healthcare work may therefore provide useful prognostic information on the risk of health impairments.

The aim of our prospective cohort study was to estimate the risk of LTSA from moderate and strenuous perceived physical exertion among 8592 healthcare workers. The healthcare workers were followed for one year in the Danish Register for Evaluation of Marginalization (DREAM), a national register of social transfer payments. We hypothesized that perceived physical exertion were associated in a dose-response manner with risk for LTSA.

\section{Methods}

\section{Study design and participants}

A questionnaire survey on health and working conditions among employees in the eldercare services of 36 Danish municipalities was merged with the DREAM register (16). The survey was conducted in 2004-2005 and included 12744 employees and yielded a response percentage of $78 \%$ ( 9947 persons). The respondents of the survey were identified by their unique personal identification number given to all Danish citizens at birth and followed in the DREAM register for one year after completion of the survey. Employees engaged in management or production of services not directly related to the provision of healthcare services (eg, kitchen staff, janitors, administrators) were excluded from the analyses $(\mathrm{N}=995)$. Furthermore, there were 360 missing replies on the questions regarding physical exertion. Thus, 8592 employees directly engaged in the provision of healthcare services in the Danish eldercare sector were included. Participants were employed as: registered nurses (3.5 years of education); social and healthcare assistants (32 months of education); social and healthcare helpers (14 months of education); "other care staff" (various care-related educations with $<12$ months of education); therapists and activity staff (this group primarily consists of physio- and occupational therapists with 3.5 years of education); and uneducated care staff and cleaners.

\section{Outcome variable: long-term sickness absence}

Data on sickness absence were obtained from the DREAM register $(16,17)$. The DREAM register con- tains weekly information on granted sickness absence, employment, education, disability pension etc for all citizens in Denmark. Sickness absence compensation is given to the employer, who can apply for a refund from the state for employees after two weeks (ie, during the third week) of sickness absence. Thus, the DREAM register contains information on sickness absence periods of $\geq 3$ consecutive weeks. LTSA was defined as the occurrence of a period of $\geq 8$ consecutive weeks of sickness absence in a 1-year follow-up period from the date of the questionnaire reply. We selected this cut-off because empirical evidence indicates that employees who are absent for $\geq 8$ weeks have a substantially increased risk of not returning to work (3). On an exploratory basis, we also tested the model with 3 consecutive weeks of sickness absence as outcome.

\section{Risk factor: perceived physical exertion during health-} care work

Participants replied to the following question based on Borg's Rate of Perceived Exertion (RPE) scale: "How would you rate your physical exertion while working with the patients?" Participants replied on a 7-point scale of (i) "very, very light", (ii) "very light", (iii) "light", (iv) "moderately strenuous", (v) "strenuous", (vi) "very strenuous", and (vii) "very, very strenuous" (18). Subsequently for the main statistical analyses, we categorized responses i-iii as "light physical exertion", iv as "moderate physical exertion" and v-vii as "strenuous physical exertion".

It should be noted that the Borg RPE scale has been validated in many different contexts to measure actual exertion, eg, perceived exertion during manual handling tasks (19-21) and not to measure exertion of the work in general. However, there are similar valid questions about physical exposure at work relating to the question used in the present study $(22,23)$.

\section{Confounders}

Potential confounders included age, gender, tenure, body mass index $\left(\mathrm{BMI}=\mathrm{kg} / \mathrm{m}^{2}\right)$, leisure-time physical activity (24), smoking status (smoker/non-smoker), psychosocial work conditions, and baseline LTSA.

One question assessed leisure-time physical activity: "Which description most precisely covers your pattern of physical activity at leisure time during the last 12 months?" with 4 response categories: (i) mainly sedentary or light physical activity for $<2$ hours per week (eg, you read, watch television, go to the cinema); (ii) light physical activity for 2-4 hours per week (eg, you go for a walk, light gardening, light physical exercise); (iii) light physical activity for $>4$ hours per week or vigorous physical exercise for 2-4 hours per week (eg, 
fast jogging or cycling, heavy gardening, exercise where you are sweating and breathing heavily); (iv) vigorous physical exercise for $>4$ hours per week or taking part in regular competitive sports several times a week $(4,24)$.

We additionally adjusted for four indicators of perceived psychosocial work conditions from the Copenhagen Psychosocial Questionnaire (COPSOQ) $(25,26)$ : (i) emotional demands (eg, "Is your work emotionally demanding?" Cronbach's $\alpha=0.81$ ); (ii) role conflicts (eg, "are contradictory demands placed on you at work?" Cronbach's $\alpha=0.66$ ); (iii) influence at work (eg, "Do you have a large degree of influence concerning your work?" Cronbach's $\alpha=0.75$ ); (iv) and quality of leadership (eg, "To what extent would you say that your immediate superior gives high priority to job satisfaction?" Cronbach's $\alpha=0.89$ ). Responses on the individual items were scored on 5-point Likert-scales with values ranging from $0-4$. According to the manual, the scores were subsequently recoded into a scale ranging from $0-100$, with 100 representing the highest degree of the measured dimension of the psychosocial work environment.

Finally, we adjusted for LTSA during one year prior to baseline, defined as weeks 1-52 before replying to the baseline questionnaire.

\section{Statistical analysis}

Using the Cox proportional hazards model, we estimated hazard ratios (HR) and $95 \%$ confidence intervals ( $95 \%$ CI) of moderate and strenuous (reference: light) perceived physical exertion for onset of LTSA during follow-up. Gender, smoking status, and leisure-time physical activity were treated as categorical variables in the analysis. Age, BMI, tenure, and the four indicators of psychosocial work conditions were treated as continuous variables. LTSA during one year prior to baseline was entered as a dichotomous variable. Respondents were followed in the DREAM register for one year and censored after the first case of LTSA. Respondents were furthermore censored in case of retirement, immigration, or death. The estimation method was maximum likelihood and the PHREG procedure of SAS 9.2 (SAS Institute, Cary, NC, USA) was used.

In model 1 , we adjusted for age and gender. In model 2, we adjusted for model 1 plus tenure, BMI, leisuretime physical activity, and smoking status. In model 3, we adjusted for model 2 plus psychosocial work conditions. In model 4, we adjusted model 3 plus LTSA during one year prior to the baseline. The results of models 1-4 are presented in table 2. Finally, we also tested model 4 with all 7 response categories from "very, very light" to "very, very strenuous" physical exertion to determine in more detail a possible dose-response relationship between perceived physical exertion and onset of LTSA (presented in figure 1).
Because the question regarding perceived exertion has not previously been validated in relation to healthcare work, we performed a Spearman correlation analysis between perceived exertion and physical workload based on the Hollmann's questionnaire asking about body postures and weight lifted during the working day (27).

\section{Results}

Table 1 presents descriptive statistics for the main study variables. Of the 8592 healthcare workers entering the study, 3019 (35.1\%), 3384 (39.4\%), and 2189 (25.5\%) experienced, respectively, light, moderate, and strenuous physical exertion during healthcare work, and $6.4 \%$ had at least one period of LTSA during the 1-year follow-up period. Healthcare workers perceiving light, moderate, and strenuous physical exertion were comparable regarding age, tenure, BMI and leisure-time physical activity. However, among healthcare workers perceiving higher levels of physical exertion, there was a higher prevalence of smokers, higher prevalence of LTSA prior to baseline, higher scores on emotional demands and role conflicts, and lower scores on influence at work and quality of leadership.

Table 2 summarizes the risk estimates from moderate and strenuous physical exertion during healthcare work for the onset of LTSA. In model 1, adjusting for age and gender, moderate and strenuous physical exertion increased the risk for LTSA by $45 \%$ and $103 \%$, respectively. Similar findings were obtained in model 2, with additional adjustments for tenure, BMI, smoking status, and leisure-time physical activity. In model 3, with additional adjustment for psychosocial work conditions, the risk estimates decreased but remained significant, and moderate and strenuous physical exertion increased the risk for LTSA by $33 \%$ and $67 \%$, respectively. In model 4 , with additional adjustment for LTSA during one year prior to baseline, these findings remained significant, and moderate and strenuous physical exertion increased the risk for LTSA by $31 \%$ and $57 \%$, respectively. All four models indicated a dose-response pattern with an approximate doubling of the risk for LTSA from moderate to strenuous physical exertion.

The strongest risk factor for LTSA during the followup year was LTSA during one year prior to baseline (HR 7.69, 95\% CI 6.24-9.47). Thus, LTSA prior to baseline increased the risk for LTSA during follow-up by $669 \%$ (model 4, not shown in table 2).

Figure 1 (model 4 using all 7 response categories) illustrates a dose-response relationship between increased perceived physical exertion during healthcare work and LTSA. The trend test for a positive associa- 
Table 1. Descriptives for the main study variables. Data are presented for the whole study population as well as for those experiencing light, moderate and strenuous physical exertion during healthcare work. [LTSA=long-term sickness absence (defined as $\geq 8$ consecutive weeks of granted sickness absence); SD=standard deviation].

\begin{tabular}{|c|c|c|c|c|c|c|c|c|c|c|c|c|}
\hline & \multirow{2}{*}{\multicolumn{3}{|c|}{ All $(\mathrm{N}=8592)$}} & \multicolumn{9}{|c|}{ Physical exertion during healthcare work } \\
\hline & & & & \multicolumn{3}{|c|}{ Light $(\mathrm{N}=3019)$} & \multicolumn{3}{|c|}{ Moderate $(\mathrm{N}=3384)$} & \multicolumn{3}{|c|}{ Strenuous $(\mathrm{N}=2189)$} \\
\hline & $\%^{a}$ & Mean & SD & $\%^{a}$ & Mean & SD & $\%^{a}$ & Mean & SD & $\%^{\text {a }}$ & Mean & SD \\
\hline LTSA (year before baseline) & 4.5 & & & 3.5 & & & 4.2 & & & 6.4 & & \\
\hline LTSA (year after baseline) & 6.4 & & & 4.6 & & & 6.4 & & & 8.9 & & \\
\hline Females & 97.5 & & & 96.8 & & & 97.7 & & & 98.2 & & \\
\hline Age (years) & & 45 & 10 & & 46 & 10 & & 45 & 10 & & 44 & 10 \\
\hline Tenure (years) & & 9 & 7 & & 9 & 7 & & 9 & 7 & & 9 & 7 \\
\hline Body mass index $\left(\mathrm{kg} / \mathrm{m}^{2}\right)$ & & 25 & 4 & & 25 & 4 & & 25 & 4 & & 25 & 5 \\
\hline Smoker & 37.0 & & & 33.8 & & & 37.6 & & & 40.5 & & \\
\hline \multicolumn{13}{|l|}{ Leisure-time physical activity } \\
\hline Low & 4.5 & & & 5.1 & & & 4.0 & & & 4.5 & & \\
\hline Medium & 41.8 & & & 41.5 & & & 42.0 & & & 42.0 & & \\
\hline High & 48.8 & & & 48.2 & & & 49.3 & & & 48.8 & & \\
\hline Very high & 4.9 & & & 5.2 & & & 4.6 & & & 4.7 & & \\
\hline \multicolumn{13}{|c|}{ Psychosocial working conditions $(0-100)$} \\
\hline Emotional demands & & 46 & 18 & & 42 & 19 & & 46 & 17 & & 52 & 19 \\
\hline Influence at work & & 45 & 20 & & 50 & 20 & & 44 & 20 & & 39 & 20 \\
\hline Role conflicts & & 42 & 16 & & 38 & 16 & & 41 & 15 & & 47 & 15 \\
\hline Quality of leadership & & 57 & 22 & & 62 & 21 & & 57 & 21 & & 50 & 22 \\
\hline
\end{tabular}

a Percentage of participants.

Table 2. Hazard ratios (HR) and 95\% confidence intervals $(95 \% \mathrm{Cl})$ for onset of long-term sickness absence ( $\geq 8$ weeks) during the 12 months follow-up for the 3 levels of perceived physical exertion during healthcare work.

\begin{tabular}{|c|c|c|c|c|c|c|c|c|}
\hline & \multicolumn{2}{|c|}{ Model $1^{\text {a }}$} & \multicolumn{2}{|c|}{ Model 2 b } & \multicolumn{2}{|c|}{ Model $3^{c}$} & \multicolumn{2}{|c|}{ Model $4^{d}$} \\
\hline & $\mathrm{HR}$ & $95 \% \mathrm{Cl}$ & $\mathrm{HR}$ & $95 \% \mathrm{Cl}$ & $\mathrm{HR}$ & $95 \% \mathrm{Cl}$ & $\mathrm{HR}$ & $95 \% \mathrm{Cl}$ \\
\hline \multicolumn{9}{|c|}{ Physical exertion } \\
\hline Light & 1 & & 1 & & 1 & & 1 & \\
\hline Moderate & 1.45 & $1.17-1.79$ & 1.50 & $1.20-1.87$ & 1.33 & $1.06-1.67$ & 1.31 & $1.04-1.64$ \\
\hline Strenuous & 2.03 & $1.63-2.52$ & 2.03 & $1.62-2.55$ & 1.67 & $1.31-2.13$ & 1.57 & $1.23-2.01$ \\
\hline
\end{tabular}

adjusted for age and gender.

b Model 1 plus adjustment for tenure, body mass index, smoking status, and leisure-time physical activity.

c Model 2 plus adjustment for psychosocial working conditions.

${ }^{d}$ Model 3 plus adjustment for long-term sickness absence (>8 weeks) during the year prior to baseline.

tion between perceived physical exertion and LTSA was highly significant $(\mathrm{P}<0.0001)$, with a HR of $1.17(95 \%$ CI 1.09-1.27) for a 1-point change on the 7-point scale. Compared with the reference category ("very, very light" physical exertion), "moderately strenuous" (HR 2.19, 95\% CI 1.12-4.28), "strenuous" (HR 2.43, 95\% CI 1.22-4.82), "very strenuous" (HR 3.05, 95\% CI $1.50-6.20$ ), and "very, very strenuous" (HR 2.99, 95\% CI 1.28-7.00) physical exertion during healthcare work were significant risk factors for LTSA. However, "very light" and "light" was not significantly different from "very, very light".

On an exploratory basis, we also tested models $1-4$ with 3 instead of 8 weeks of sickness absence. During the year prior to baseline and during the 1-year followup, $13.3 \%$ and $14.6 \%$ experienced at least 3 consecu- tive weeks of sickness absence, respectively. The risk estimates for 3 weeks of sickness absence were broadly similar as those obtained for 8 consecutive weeks of sickness absence (table 3).

Perceived exertion was positively correlated with physical workload as assessed by the Holmann Index, with a correlation coefficient of $0.47(\mathrm{P}<0.001)$.

\section{Discussion}

In this study, we prospectively followed 8592 healthcare workers with varying degrees of perceived physical exertion during healthcare work in a national register on social transfer payments. The results showed an 


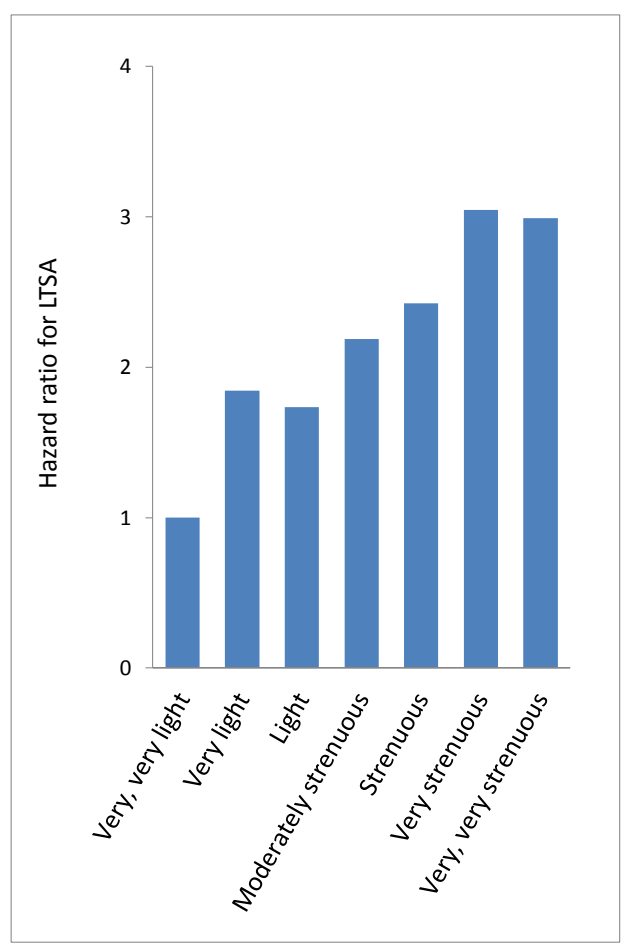

Figure 1. Hazard ratios (HR) for long-term sickness absence (LTSA) from "very, very light" (reference) to "very, very strenuous" physical exertion during healthcare work among 8592 healthcare workers followed prospectively for one year in a national register of social transfer payment. The trend test was significant $(P<0.0001)$. Adjusted for age, gender, tenure, body mass index, leisure-time physical activity, psychosocial working conditions and LTSA during the year prior to baseline.

Table 3. Hazard ratios (HR) and 95\% confidence intervals (95\% $\mathrm{Cl}$ ) for onset of 3 consecutive weeks of sickness absence during the 12 months follow-up for the 3 levels of perceived physical exertion during healthcare work.

\begin{tabular}{|c|c|c|c|c|c|c|c|c|}
\hline & \multicolumn{2}{|c|}{ Model $1^{\mathrm{a}}$} & \multicolumn{2}{|c|}{ Model $2^{b}$} & \multicolumn{2}{|c|}{ Model $3^{c}$} & \multicolumn{2}{|c|}{ Model $4^{d}$} \\
\hline & $\mathrm{HR}$ & $95 \% \mathrm{Cl}$ & $\mathrm{HR}$ & $95 \% \mathrm{Cl}$ & $\mathrm{HR}$ & $95 \% \mathrm{Cl}$ & $\mathrm{HR}$ & $95 \% \mathrm{Cl}$ \\
\hline \multicolumn{9}{|c|}{ Physical exertion } \\
\hline Light & 1 & & 1 & & 1 & & 1 & \\
\hline Moderate & 1.36 & $1.19-1.57$ & 1.39 & $1.21-1.60$ & 1.31 & $1.13-1.52$ & 1.28 & $1.10-1.48$ \\
\hline Strenuous & 1.83 & $1.58-2.11$ & 1.81 & $1.56-2.10$ & 1.62 & $1.38-1.9$ & 1.53 & $1.30-1.79$ \\
\hline
\end{tabular}

a Adjusted for age and gender

${ }^{\mathrm{b}}$ Model 1 plus adjustment for tenure, BMI, smoking status, and leisure-time physical activity.

c Model 2 plus adjustment for psychosocial working conditions.

a Model 3 plus adjustment for 3 consecutive weeks of sickness absence during the year prior to baseline.

increased risk for LTSA from moderate and strenuous perceived physical exertion during healthcare work. The risk for LTSA increased with increased physical exertion in a dose-response manner.

Our results on perceived physical exertion and LTSA are in agreement with previous findings on physical work demands and LTSA in the general working population (8). The overall results did not change when we used three instead of eight consecutive weeks of sickness absence as outcome. This shows that perceived physical exertion is a relevant risk factor for both shorter and longer spells of sickness absence. Healthcare work inherently involves physically demanding tasks such as lifting, bending, and twisting while handling patients. In several reviews, researchers have reported evidence for an association between occupational risk factors, such as lifting, bending, and twisting of the trunk, and musculoskeletal disorders among different occupational groups (28-30). By contrast, a systematic review by Roffey and coworkers found no support for a causal relationship between manual handling or assisting patients and prospective development of poor health among healthcare workers (31). In the prospective cohort studies reviewed, questions on physical work demands were used to describe the actual work, eg, varying tasks of manual handling and assisting patients (eg, 32). While such questions provide important information on specific physical risk factors in the work environment, perceived exertion adds the dimension of the individual perception of work demands relative to the capacity to perform the 
work. Asking a single question on perceived physical exertion, we showed that the individual perception of workload provides important prognostic information for the risk of LTSA.

The main statistical analysis with the categories light, moderate, and strenuous physical exertion (table 2) indicated a possible dose-response association between perceived exertion and LTSA. To investigate this in more detail, we included all 7 response categories in the analysis (figure 1), and showed that the risk for LTSA increased with increased physical exertion in a doseresponse manner (ie, the trend test was highly significant). However, the categories "very light" and "light" did not pose significantly higher risks than "very, very light" physical exertion, indicating an offset for the risk of LTSA with moderate physical exertion. Furthermore, the wide and overlapping confidence intervals indicate a lack of statistical power to detect solid differences when including all 7 response categories.

Previous studies point toward an association between perceived psychosocial work conditions and sickness absence $(17,25,33-35)$. It can be speculated that a general negative social climate makes employees more prone to report higher physical exertion or that psychosocial work factors per se are associated with sickness absence. For these reasons, we controlled for four typical psychosocial work factors: (i) emotional demands, (ii) role conflicts, (iii) influence at work, and (iv) quality of leadership. Although adjusting for these factors decreased the risk estimates by one third, the findings remained significant as shown in table 2. In the Danish work environment cohort study, Lund and coworkers (8) found an interaction between psychosocial work conditions and physical work demands. The influence of perceived physical exertion was not investigated in that study. Altogether, this calls for future analyses of the interaction between perceived physical exertion and psychosocial work conditions among healthcare workers.

Our results indicate that preventive initiatives should aim to balance physical work demands with the physical capacity of the worker. This could be achieved either by lowering physical work demands (eg, by using manual handling equipment) or increasing the physical capacity of the worker (eg, by regular physical exercise). In the present study, we found a positive correlation between perceived exertion and physical workload as assessed by the Hollmann questionnaire, indicating that lowering physical workload can reduce perceived exertion. However, we had no objective measures of physical workload, and a significant relation between two questionnaire scores may be biased by common rater effects. Strong evidence exists for effectiveness of physical exercise programs in preventing episodes of back pain among adults (36). However, due to a lack of high-quality randomized controlled trials, conflict- ing evidence exists for the effectiveness of exercise programs and provision of manual handling equipment among healthcare workers (37). Thus, high-quality randomized controlled trials evaluating initiatives reducing perceived physical exertion for the prevention of LTSA are recommended.

Our study has both strengths and weaknesses. A strength is the large sample size of $>8000$ healthcare workers followed in a national register. The inclusion of 36 different municipalities and the high initial response percentage to the baseline questionnaire improves the external validity of the study. However, the preponderance of women limits the generalizability of our findings to female healthcare workers. On the other hand, this merely reflects that the labor market for healthcare workers is gender segregated. From this perspective, the results seem highly relevant. Using a national register on social transfer payments to determine LTSA strengthened our study as we eliminated any recall and non-response bias during follow-up. Also, adjustment for several confounders - including psychosocial work conditions, lifestyle factors, and sickness absence prior to baseline - strengthens the validity of our findings.

In conclusion, moderate and strenuous perceived physical exertion during healthcare work increases the risk for LTSA in a dose-response manner. The possible preventive effect of balancing work demands with the capacity of the worker should be tested in randomized controlled trials.

\section{Acknowledgments}

The study was supported by a grant from the Danish Parliament (SATS 2004).

The authors declare no conflicts of interest.

\section{References}

1. Simoens S, Villeneuve M, Hurst J. Tackling nurse shortages in OECD countries. OECD health working papers, no.19. Paris: OECD Publications Services; 2005. http://dx.doi. org/10.1787/172102620474.

2. Lund T, Labriola M, Villadsen E. Who is at risk for longterm sickness absence? A prospective cohort study of Danish employees. Work. 2007;28(3):225-30.

3. Høgelund J, Filges T, Jensen S. Long-term sickness absence - what happens and how does it go? Copenhagen: The Danish National Institute of Social Research; 2003.

4. Andersen LL, Clausen T, Mortensen OS, Burr H, Holtermann A. A prospective cohort study on musculoskeletal risk factors for long-term sickness absence among healthcare workers in eldercare. Int Arch Occup Environ Health. 2011 Oct 11. [Epub

Scand J Work Environ Health 2012, vol 38, no 6 
ahead of print]. http://dx.doi.org/10.1007/s00420-011-0709-5.

5. Henderson M, Glozier N, Holland EK. Long term sickness absence. BMJ. 2005 Apr 9;330(7495):802-3. http://dx.doi. org/10.1136/bmj.330.7495.802.

6. Waddell G, Burton K. Is Work Good for Your Health and Wellbeing? London: The Stationary Office; 2006.

7. van den Berg TI, Elders LA, de Zwart BC, Burdorf A. The effects of work-related and individual factors on the Work Ability Index: a systematic review. Occup Environ Med. 2009 Apr;66(4):211-20. http://dx.doi.org/10.1136/ oem.2008.039883.

8. Lund T, Labriola M, Christensen KB, Bultmann U, Villadsen E. Physical work environment risk factors for long term sickness absence: prospective findings among a cohort of 5357 employees in Denmark. BMJ. 2006 Feb 25;332(7539):449-52. http://dx.doi.org/10.1136/bmj.38731.622975.3A.

9. Torgen M, Nygard CH, Kilbom A. Physical work load, physical capacity and strain among elderly female aides in home-care service. Eur J Appl Physiol Occup Physiol 1995;71(5):444-52. http://dx.doi.org/10.1007/BF00635879.

10. Holtermann A, Jorgensen MB, Gram B, Christensen JR, Faber A, Overgaard K, et al. Worksite interventions for preventing physical deterioration among employees in jobgroups with high physical work demands: background, design and conceptual model of FINALE. BMC Public Health. 2010;10:120. http://dx.doi.org/10.1186/1471-2458-10-120.

11. Pohjonen T. Age-related physical fitness and the predictive values of fitness tests for work ability in home care work. J Occup Environ Med. 2001 Aug;43(8):723-30. http://dx.doi. org/10.1097/00043764-200108000-00011.

12. Borg G, Lindenholm H. Perceived Exertion and Pulse Rate during Graded Exercise in Various Age Groups. Acta Med Scand. 1967; Suppl 472:194-206.

13. Andersen LL, Andersen $\mathrm{CH}$, Mortensen OS, Poulsen $\mathrm{OM}$, Bjornlund IB, Zebis MK. Muscle activation and perceived loading during rehabilitation exercises: comparison of dumbbells and elastic resistance. Phys Ther. 2010 Apr;90(4):538-49. http://dx.doi.org/10.2522/ptj.20090167.

14. Feng CK, Chen ML, Mao IF. Prevalence of and risk factors for different measures of low back pain among female nursing aides in Taiwanese nursing homes. BMC Musculoskelet Disord. 2007;8:52. http://dx.doi.org/10.1186/1471-2474-8-52.

15. Smith DR, Mihashi M, Adachi Y, Koga H, Ishitake T. A detailed analysis of musculoskeletal disorder risk factors among Japanese nurses. J Safety Res. 2006;37(2):195-200. http://dx.doi.org/10.1016/j.jsr.2006.01.004.

16. Hjollund NH, Larsen FB, Andersen JH. Register-based followup of social benefits and other transfer payments: accuracy and degree of completeness in a Danish interdepartmental administrative database compared with a population-based survey. Scand J Public Health. 2007;35(5):497-502. http:// dx.doi.org/10.1080/14034940701271882.

17. Lund T, Labriola M, Christensen KB, Bultmann U, Villadsen E, Burr H. Psychosocial work environment exposures as risk factors for long-term sickness absence among Danish employees: results from DWECS/DREAM. J Occup Environ
Med. 2005 Nov;47(11):1141-7. http://dx.doi.org/10.1097/01. jom.0000174301.80318.f2

18. Borg G. Borg's perceived exertion and pain scales. IL : HK, USA: Champaign; 1998. 2-104 p.

19. Capodaglio P, Bazzini G. Tolerability to prolonged lifting tasks. A validation of the recommended limits. G Ital Med Lav Ergon. 1997 Jul;19(3):72-5.

20. Borg G. Psychophysical scaling with applications in physical work and the perception of exertion. Scand J Work Environ Health. 1990;16 Suppl 1:55-8. http://dx.doi.org/10.5271/ sjweh.1815.

21. Gamberale F. Perception of effort in manual materials handling. Scand J Work Environ Health. 1990;16 Suppl 1:59-66. http://dx.doi.org/10.5271/sjweh.1820.

22. Kwak L, Proper KI, Hagstromer M, Sjostrom M. The repeatability and validity of questionnaires assessing occupational physical activity--a systematic review. Scand J Work Environ Health. 2011 Jan;37(1):6-29. http://dx.doi. org/10.5271/sjweh.3085.

23. Stock SR, Fernandes R, Delisle A, Vezina N. Reproducibility and validity of workers' self-reports of physical work demands. Scand J Work Environ Health. 2005 Dec;31(6):409-37. http:// dx.doi.org/10.5271/sjweh.947.

24. Saltin B, Grimby G. Physiological analysis af middle-aged and old former athletes. Circulation. 1968;38:1104-15.

25. Clausen T, Nielsen K, Carneiro IG, Borg V. Job demands, job resources and long-term sickness absence in the Danish eldercare services: a prospective analysis of register-based outcomes. J Adv Nurs. 2011 Jun 9;68(1):127-36. http://dx.doi. org/10.1111/j.1365-2648.2011.05724.x.

26. Pejtersen JH, Kristensen TS, Borg V, Bjorner JB. The second version of the Copenhagen Psychosocial Questionnaire. Scand J Public Health.2010 Feb;38(3 Suppl):8-24. http://dx.doi. org/10.1177/1403494809349858.

27. Hollmann S, Klimmer F, Schmidt KH, Kylian H. Validation of a questionnaire for assessing physical work load. Scand J Work Environ Health. 1999 Apr;25(2):105-14. http://dx.doi. org/10.5271/sjweh.412.

28. Kuiper JI, Burdorf A, Verbeek JH, Frings-Dresen M, van der Beek A, Viikari-Juntura E. Epidemiological evidence on manual material handling as a risk factor for back disorders: a systematic review. Int J Ind Erg. 1999;24:389-404. http:// dx.doi.org/10.1016/S0169-8141(99)00006-2.

29. Hoogendoorn WE, van Poppel MNM, Bongers PM, Koes BW, Bouter LM. Physical load during work and leisure time as risk factors for back pain. Scand J Work Environ Health. 1999;25(5):387-403. http://dx.doi.org/10.5271/sjweh.451.

30. Lotters F, Burdorf A, Kuiper J, Miedema H. Model for the work-relatedness of low-back pain. Scand J Work Environ Health. 2003 Dec;29(6):431-40. http://dx.doi.org/10.5271/ sjweh.749.

31. Roffey DM, Wai EK, Bishop P, Kwon BK, Dagenais S. Causal assessment of workplace manual handling or assisting patients and low back pain: results of a systematic review. Spine J. 2010 Jul;10(7):639-51. http://dx.doi.org/10.1016/j. spinee.2010.04.028. 
32. Eriksen W, Bruusgaard D, Knardahl S. Work factors as predictors of intense or disabling low back pain; a prospective study of nurses' aides. Occup Environ Med. 2004 May;61(5):398-404. http://dx.doi.org/10.1136/ oem.2003.008482.

33. Ala-Mursula L, Vahtera J, Kivimaki M, Kevin MV, Pentti J. Employee control over working times: associations with subjective health and sickness absences. J Epidemiol Community Health. 2002 Apr;56(4):272-8. http://dx.doi. org/10.1136/jech.56.4.272.

34. Voss M, Floderus B, Diderichsen F. Physical, psychosocial, and organisational factors relative to sickness absence: a study based on Sweden Post. Occup Environ Med. 2001 Mar;58(3):178-84. http://dx.doi.org/10.1136/oem.58.3.178.
35. Eshoj P, Jepsen JR, Nielsen CV. Long-term sickness absence - risk indicators among occupationally active residents of a Danish county. Occup Med (Lond). 2001 Aug;51(5):347-53. http://dx.doi.org/10.1093/occmed/51.5.347.

36. Bigos SJ, Holland J, Holland C, Webster JS, Battie M, Malmgren JA. High-quality controlled trials on preventing episodes of back problems: systematic literature review in working-age adults. Spine J. 2009 Feb;9(2):147-68. http:// dx.doi.org/10.1016/j.spinee.2008.11.001.

37. Dawson AP, McLennan SN, Schiller SD, Jull GA, Hodges PW, Stewart S. Interventions to prevent back pain and back injury in nurses: a systematic review. Occup Environ Med. 2007 Oct;64(10):642-50. http://dx.doi.org/10.1136/ oem.2006.030643.

Received for publication: 1 December 2011 